\title{
Factors Associated with an Absence of Effect of an Education Program for Improving Knowledge of Schizophrenia
}

\author{
Hatsumi Yoshii ${ }^{1}$, Yuichiro Watanabe ${ }^{2,3}$, Hideaki Kitamura $^{2}$, Yoshitaka Sakai ${ }^{4} \&$ Kouhei Akazawa ${ }^{4}$ \\ ${ }^{1}$ School of Health Sciences, Faculty of Medicine, Tohoku University, Sendai, Japan \\ ${ }^{2}$ Department of Psychiatry, Niigata University Graduate School of Medical and Dental Sciences, Niigata, Japan \\ ${ }^{3}$ Division of Medical Education, Comprehensive Medical Education Center, School of Medicine, Faculty of \\ Medicine, Niigata University, Niigata, Japan \\ ${ }^{4}$ Department of Medical Informatics and Statistics, Niigata University Graduate School of Medicine, Niigata, \\ Japan \\ Correspondence: Hatsumi Yoshii, School of Health Sciences, Faculty of Medicine, Tohoku University, 2-1 \\ Seiryo-cho, Aoba-ku, Sendai-City, Miyagi-Prefecture, 980-8575 Japan. Tel: 81-22-717-7954. E-mail: \\ hatsumi@med.tohoku.ac.jp
}

Received: April 26, 2012 Accepted: May 11, 2012 Online Published: May 22, 2012

doi:10.5539/gjhs.v4n4p42 URL: http://dx.doi.org/10.5539/gjhs.v4n4p42

This work was supported by a 2010 Grant-in-Aid for Scientific Research (C) from the Japan Society for the Promotion of Science (22592581), entitled Investigations of the Consciousness of Parents of Junior and Senior High School Students Concerning Schizophrenia and the Development of Educational Enlightenment Media

\begin{abstract}
Schizophrenia can develop in junior and senior high school students. Correct identification of schizophrenia symptoms is an important factor in subsequent healthcare. The present study conducted a multifaceted evaluation of factors associated with an absence of effect of an education program for improving knowledge of schizophrenia among parents of Japanese junior and senior high school students. Regarding discrimination of prodromal symptoms, the factors associated with an absence of effect of the education program were graduate school education, family income $>110000$ USD, proximity to a person with schizophrenia, employment as a professional, and participation in welfare activities for people with mental illness. Regarding discrimination of schizophrenia, the factors associated with an absence of effect were a family income of 53000 to 110000 USD $(\mathrm{P}<0.05)$, and employment in production/labor service $(\mathrm{P}<0.05)$.
\end{abstract}

Keywords: parents, education program, schizophrenia

\section{Introduction}

Schizophrenia is a serious illness that usually manifests in adolescence or early adulthood (Koning et al., 2009). People with schizophrenia usually experience their first psychotic symptoms before age 20 years (Chong et al., 2004), and the illness can develop in junior and senior high school students. The prognosis for young people is unfavorable (Torrey, 2006), and longer duration of untreated psychosis (DUP) is associated with undesirable outcomes such as delay in remission and an adverse prognosis (Van et al., 2005; Yamazawa et al., 2004; Yung et al., 2007). When left unrecognized, untreated, or poorly treated, psychotic illnesses during adolescence can lead to considerable personal and family distress and increased illness severity. They also contribute to poor academic performance, premature exit from school, unemployment, sustained disability, and early death (Yung et al., 2007). These findings indicate that prompt intervention is critical in ensuring better outcomes. However, several studies have shown an average gap of one or two years between onset of psychosis and beginning of treatment (Boydell et al., 2006). Extensive delays in access to treatment are common after the first episode of a psychotic illness (Lincoln et al., 1995). In general, patients were unaware of their symptoms and reluctant to seek assistance from mental health professionals after their first psychotic episode (Bechard-Evans et al., 2007). Therefore, it is important for parents of junior and senior high school students to be aware of the signs of such episodes in their children. Few studies have assessed whether parents of junior and senior high school students can discriminate symptoms of schizophrenia from symptoms of other physical and psychiatric illnesses. The 
present authors developed and studied a web-based education program that aimed to improve understanding of schizophrenia among 2465 Japanese parents of junior and senior high school students. This study quantitatively evaluated the factors associated with an absence of effect for this education program on improving parental knowledge of schizophrenia symptoms. The findings are likely to be important in developing education programs for early intervention in schizophrenia.

\section{Methods}

\subsection{Participants}

The participants were selected from an enormous database of 1370000 candidates, which was administered by a private Japanese company that specializes in questionnaire research. Stratified random sampling was used to prevent sample bias, and the analysis was stratified by gender and region. Our sample was 2465 parents of junior and senior high school students. All participants completed a questionnaire on an internet website, the details of which have been previously described (Yoshii et al., 2011). Consent from the participants was obtained by the company that administered the database, and the study was approved by the medical ethics committee of Niigata University.

\subsection{Questionnaire}

The questionnaire was used to collect demographic information on the respondents (eg, gender, education) and information on discrimination of symptoms. The questions were based on the Diagnostic and Statistical Manual of Mental Disorders, Fourth Edition, Text Revision (DSM-IV-TR) criteria for schizophrenia and on the PRIME-Screen (Kobayashi et al., 2008). The questionnaire comprised 4 items on schizophrenia symptoms, 4 items on prodromal symptoms, and 11 other items. On these scales, higher total scores indicate better discrimination. Parents viewed the education program, and the questionnaire was answered again after 1 week. These are referred to as the "before" and "after" questionnaires. The details of the questionnaire have been previously described (Yoshii et al., 2011).

\subsection{Web-based Education Program}

A web-based education program was developed to improve understanding of schizophrenia. It described the positive and negative symptoms of schizophrenia, as well as the prodromal symptoms of schizophrenia. It comprised 12 narrated slides and required 13 minutes to complete. All parents were invited to view this web-based education program, as previously described (Yoshii et al., 2011).

\subsection{Statistical Analysis}

Analyses were done using the SPSS Version 16.0. Correct answer scores were calculated by dividing the subtract the "before" questionnaire from the "after" questionnaire with those on for all respondents by the number of items. The Student or Welch t-test and one-way analysis of variance were used to identify the education program factors that had no effect. The Kruskal-Wallis test and Mann-Whitney $U$ test were used to examine the associations between the score on the "before" questionnaire and the demographic characteristics of participants. A $p$ value $<0.05$ was considered to indicate statistical significance, and all statistical tests were two-tailed.

\section{Results}

\subsection{Characteristics of Participants}

The participants were 2465 Japanese parents of junior and senior high school students: $1381(56.02 \%)$ men and 1084 (43.98\%) women. Regarding family structure, 1921 (77.93\%) household had 2 parents, 82 (3.33\%) had 1 parent, and $424(17.20 \%)$ comprised 3 generations. Regarding occupation, $585(23.73 \%)$ were employed in production/labor service and $523(21.22 \%)$ were unemployed. A total of $206(8.36 \%)$ parents had experience participating in mental-health welfare activities (Yoshii et al., 2011).

\subsection{Factors Associated with an Absence of Effect of the Education Program}

Regarding discrimination of schizophrenia, family income $(\mathrm{P}<0.05)$ and occupation $(\mathrm{P}<0.05)$ were associated with an absence of effect of the education program (Table 1). The lowest mean $( \pm \mathrm{SD})$ scores for discrimination of schizophrenia were $0.47 \pm 1.57$ among those with a family income of 53000 to 110000 USD and $0.38 \pm 1.59$ for those employed in production/labor service. Regarding the score on the "before" questionnaire, the results of the Kruskal-Wallis test showed no significant difference between participants categorized by occupation and those categorized by family income ( $\mathrm{P}>0.05$; Table 2$)$. 
Table 1. Factors associated with an absence of effect of the education program

\begin{tabular}{|c|c|c|c|c|c|}
\hline & \multirow[t]{2}{*}{$\mathbf{n}$} & \multicolumn{2}{|c|}{$\begin{array}{l}\text { Discrimination of } \\
\text { schizophrenia }\end{array}$} & \multicolumn{2}{|c|}{$\begin{array}{c}\text { Discrimination of prodromal } \\
\text { symptoms }\end{array}$} \\
\hline & & Mean \pm SD & $P^{*}$ & Mean \pm SD & $P^{*}$ \\
\hline Age (years) & & & 0.276 & & 0.347 \\
\hline $30-39$ & 196 & $0.36 \pm 1.42$ & & $1.48 \pm 1.95$ & \\
\hline $40-49$ & 1743 & $0.55 \pm 1.62$ & & $1.20 \pm 2.04$ & \\
\hline $50-59$ & 512 & $0.60 \pm 1.65$ & & $1.24 \pm 2.13$ & \\
\hline $60-69$ & 14 & $0.21 \pm 2.05$ & & $1.21 \pm 2.58$ & \\
\hline Gender & & & 0.937 & & 0.567 \\
\hline Male & 1298 & $0.54 \pm 1.61$ & & $1.26 \pm 2.13$ & \\
\hline Female & 1167 & $0.55 \pm 1.61$ & & $1.21 \pm 1.98$ & \\
\hline Education & & & 0.745 & & 0.001 \\
\hline Junior high school & 25 & $0.80 \pm 1.29$ & & $1.72 \pm 2.17$ & \\
\hline High school & 690 & $0.55 \pm 1.57$ & & $1.53 \pm 1.90$ & \\
\hline Vocational school & 310 & $0.61 \pm 1.64$ & & $1.24 \pm 2.08$ & \\
\hline Junior college & 355 & $0.58 \pm 1.65$ & & $1.02 \pm 1.94$ & \\
\hline University & 990 & $0.51 \pm 1.62$ & & $1.18 \pm 2.15$ & \\
\hline Graduate school & 91 & $0.46 \pm 1.75$ & & $0.29 \pm 2.08$ & \\
\hline Others & 4 & $1.50 \pm 2.38$ & & $1.00 \pm 1.83$ & \\
\hline Family structure & & & 0.303 & & 0.551 \\
\hline 2 parents & 1921 & $0.55 \pm 1.63$ & & $1.21 \pm 2.08$ & \\
\hline 1 parent & 82 & $0.80 \pm 1.67$ & & $1.20 \pm 1.98$ & \\
\hline 3 generations & 424 & $0.47 \pm 1.53$ & & $1.36 \pm 1.97$ & \\
\hline Others & 38 & $0.76 \pm 1.67$ & & $1.29 \pm 1.99$ & \\
\hline Family income (US dollars) & & & 0.008 & & 0.002 \\
\hline$<11000$ & 37 & $1.00 \pm 1.43$ & & $1.59 \pm 1.98$ & \\
\hline $11000-32000$ & 181 & $0.81 \pm 1.82$ & & $1.54 \pm 1.87$ & \\
\hline $32000-53000$ & 465 & $0.67 \pm 1.64$ & & $1.40 \pm 1.99$ & \\
\hline $53000-110000$ & 1326 & $0.47 \pm 1.57$ & & $1.22 \pm 2.05$ & \\
\hline$>110000$ & 456 & $0.51 \pm 1.62$ & & $0.95 \pm 2.19$ & \\
\hline Proximity to person with schizophrenia & & & 0.498 & & 0.006 \\
\hline Yes & 78 & $0.42 \pm 1.40$ & & $0.60 \pm 2.25$ & \\
\hline No & 2387 & $0.55 \pm 1.62$ & & $1.25 \pm 2.05$ & \\
\hline Occupation & & & 0.028 & & 0.001 \\
\hline Agriculture, forestry, and fisheries & 8 & $1.75 \pm 1.67$ & & $1.50 \pm 1.51$ & \\
\hline Production/labor service & 585 & $0.38 \pm 1.59$ & & $1.39 \pm 2.09$ & \\
\hline Transportation and communication & 134 & $0.46 \pm 1.58$ & & $1.34 \pm 2.27$ & \\
\hline Sales and marketing & 315 & $0.61 \pm 1.57$ & & $1.13 \pm 2.02$ & \\
\hline Service industry & 305 & $0.72 \pm 1.73$ & & $1.31 \pm 2.02$ & \\
\hline Professionals & 442 & $0.55 \pm 1.57$ & & $0.83 \pm 2.05$ & \\
\hline Others & 153 & $0.53 \pm 1.65$ & & $1.09 \pm 2.01$ & \\
\hline Unemployed & 523 & $0.59 \pm 1.62$ & & $1.42 \pm 2.00$ & \\
\hline $\begin{array}{l}\text { Participation in welfare activities for } \\
\text { people with mental illness }\end{array}$ & & & 0.338 & & 0.001 \\
\hline Yes & 206 & $0.44 \pm 1.67$ & & $0.69 \pm 2.21$ & \\
\hline No & 2259 & $0.55 \pm 1.61$ & & $1.28 \pm 2.04$ & \\
\hline
\end{tabular}

Correct answer scores were calculated by dividing the subtract the "before" questionnaire from the "after" questionnaire with those on for all respondents by the number of items. * Student or Welch t-test and one-way analysis of variance. 
Table 2. Scores on "before" questionnaire (factors associated with an absence of effect of the education program)

\begin{tabular}{|c|c|c|c|c|c|}
\hline & \multirow[t]{2}{*}{$\mathbf{n}$} & \multirow{2}{*}{$\begin{array}{r}\begin{array}{r}\text { Discrimination o } \\
\text { schizophrenia }\end{array} \\
\text { Maximum score: } 4 \\
\text { Median }(25 \%, 75 \%)\end{array}$} & \multirow{2}{*}{ f } & \multicolumn{2}{|c|}{$\begin{array}{l}\text { Discrimination of prodromal } \\
\text { symptoms }\end{array}$} \\
\hline & & & & $\begin{array}{l}\text { Maximum score: } 4 \\
\text { Median }(25 \%, 75 \%)\end{array}$ & $P$ \\
\hline Education & & & & & 0.001 \\
\hline Junior high school & 25 & - & & $0.00(0.00,2.00)$ & \\
\hline High school & 690 & - & & $1.00(0.00,2.00)$ & \\
\hline Vocational school & 310 & - & & $1.00(0.00,2.00)$ & \\
\hline Junior college & 355 & - & & $1.00(0.00,2.00)$ & \\
\hline University & 990 & - & & $1.00(0.00,2.00)$ & \\
\hline Graduate school & 91 & - & & $2.00(1.00,3.00)$ & \\
\hline Others & 4 & - & & $1.00(0.25,2.50)$ & \\
\hline Occupation & & & 0.990 & & 0.037 \\
\hline Agriculture, forestry, and fisheries & 8 & - & & $0.00(0.00,2.00)$ & \\
\hline Production/labor service & 585 & - & & $1.00(0.00,2.00)$ & \\
\hline Transportation and communication & 134 & - & & $1.00(0.00,2.00)$ & \\
\hline Sales and marketing & 315 & - & & $1.00(0.00,2.00)$ & \\
\hline Service industry & 305 & - & & $1.00(0.00,2.00)$ & \\
\hline Professionals & 442 & - & & $1.00(0.00,3.00)$ & \\
\hline Others & 153 & - & & $1.00(0.00,2.00)$ & \\
\hline Unemployed & 523 & - & & $1.00(0.00,2.00)$ & \\
\hline Family income (US dollars) & & & 0.128 & & 0.001 \\
\hline$<11000$ & 37 & - & & $1.00(0.00,2.00)$ & \\
\hline $11000-32000$ & 181 & - & & $1.00(0.00,2.00)$ & \\
\hline $32000-53000$ & 465 & - & & $1.00(0.00,2.00)$ & \\
\hline $53000-110000$ & 1326 & - & & $1.00(0.00,2.00)$ & \\
\hline$>110000$ & 456 & - & & $1.00(0.00,2.00)$ & \\
\hline Proximity to person with schizophrenia & & & & & 0.001 \\
\hline Yes & 78 & - & & $2.00(0.00,3.00)$ & \\
\hline No & 2387 & - & & $1.00(0.00,2.00)$ & \\
\hline $\begin{array}{l}\text { Participation in welfare activities for } \\
\text { people with mental illness }\end{array}$ & & & & & 0.001 \\
\hline Yes & 206 & - & & $1.00(0.00,3.00)$ & \\
\hline No & 2259 & - & & $1.00(0.00,2.00)$ & \\
\hline
\end{tabular}

* Kruskal-Wallis test, Mann-Whitney U test

Regarding discrimination of prodromal symptoms, the factors associated with an absence of effect of the education program were education $(\mathrm{P}<0.05)$, family income $(\mathrm{P}<0.05)$, proximity to a person with schizophrenia $(\mathrm{P}<0.05)$, occupation $(\mathrm{P}<0.05)$, and participation in welfare activities for people with mental illnesses $(\mathrm{P}<0.05$; Table 1). The lowest mean $( \pm \mathrm{SD})$ scores for discrimination of prodromal symptoms were $0.29 \pm 2.08$ for graduate school education, $0.95 \pm 2.19$ for a family income $>110000$ USD, $0.60 \pm 2.25$ for proximity to a person with schizophrenia, $0.83 \pm 2.05$ for employment as a professional, and $0.69 \pm 2.21$ for participation in welfare activities for people with mental illnesses. Regarding the score on the "before" questionnaire, the Kruskal-Wallis test and 
Mann-Whitney U test showed associations between the dependent variable (base of knowledge) and independent variables (demographic characteristics). It was significantly associated with education, occupation, family income, proximity to a person with schizophrenia, and participation in welfare activities for people with mental illnesses ( $\mathrm{P}<0.05$; Table 2).

\section{Discussion}

Schizophrenia tends to have a chronic course and can result in considerable disability. Early intervention might improve both response to antipsychotic treatment and long-term outcome (Yoshii et al., 2012). Awareness of a mental disorder at onset was reported to be related to shorter DUP (Yamazawa et al., 2004). In a series of Australian studies, poor mental-health literacy was a significant barrier to appropriate help-seeking among youths and adults. Because schizophrenia can develop even in junior and senior high school students, a better understanding of the disorder among the parents of adolescents could lead to earlier recognition and intervention (Bechard-Evans et al., 2007; Yung et al., 2007). Thus, developed a schizophrenia education program has been developed for parents of adolescents in Japan.

The present study conducted a multifaceted evaluation of the factors associated with an absence of effect of the education program on improving schizophrenia knowledge among parents of junior and senior high school students. The present study tested the hypothesis that older age would be associated with an absence of effect. The present findings, which confirm those of Farrer, showed that although older adults ( $\geq 70$ years) were indeed less able than younger age groups to correctly recognize depression and schizophrenia, the lower scores for discrimination of schizophrenia and discrimination of prodromal symptoms did not significantly differ by age. Therefore, age was not associated with the effect of education.

Most people who develop schizophrenia experience a prodromal phase of functioning before the onset of psychotic symptoms. This prodromal phase includes depressed mood, anxiety, irritability, changes in volition, cognitive changes, physical symptoms, behavioral changes, impaired tolerance to normal stress, and attenuated psychotic symptoms. Prodromal symptoms are generally nonspecific (Yoshii et al., 2011). Our educational program improved the ability to distinguish prodromal symptoms (Yoshii et al., 2011). The factors associated with an absence of effect of the education program were those associated with the highest baseline scores for discrimination of prodromal symptoms, ie, graduate school education, family income $>110000$ USD, proximity to a person with schizophrenia, employment as a professional, and participation in welfare activities for people with mental illnesses. Knowledge did not increase among people who were already knowledgeable. In other words, the education program had a positive effect among people who did not already know about prodromal symptoms. These results were somewhat disappointing, as it was hoped that the education program would have a broader educational impact.

A low score on a test that measured ability to discriminate schizophrenia was associated with prolongation of DUP (Bechard-Evans et al., 2007; Yung et al., 2007). Therefore, it is important for parents to be able to recognize the symptoms of schizophrenia. Our educational program was able to improve this ability (Yoshii et al., 2011). Therefore, it might be useful in facilitating early intervention. Individuals who reported a family history of psychiatric treatment or a friend with a history of psychiatric treatment had higher knowledge scores than did those without those characteristics (Esterberg et al., 2008). In the present study, the factors associated with an absence of effect of the education program were a family income 53000 to 110000 USD and employment in the production/labor service. These factors didn't the high at base of knowledge.

\section{Conclusions}

In discriminating prodromal symptoms, the factors associated with an absence of effect of the education program were graduate school education, family income $>110000$ USD, proximity to a person with schizophrenia, employment as a professional, and participation in welfare activities for people with mental illnesses. In discriminating schizophrenia, the factors associated with an absence of effect were a family income of 53000 to 110000 USD and employment in the production/labor service $(\mathrm{P}<0.05)$.

\section{Acknowledgements}

The authors thank the study participants. 


\section{References}

Bechard-Evans, L., Schmitz, N., Abadi, S., Joober, R., King, S., \& Malla, A. (2007). Determinants of help-seeking and system related components of delay in the treatment of first-episode psychosis. Schizophr Res., 96, 206-214. http://dx.doi.org/10.1016\%2Fj.schres.2007.07.017

Boydell, K. M., Gladstone, B. M., \& Volpe, T. (2006). Understanding help seeking delay in the prodrome to first episode psychosis: a secondary analysis of the perspectives of young people. Psychiatric Rehabilitation journal, 30, 54-60. http://dx.doi.org/10.2975\%2F30.2006.54.60

Chong, S. A., Lee, C., Bird, L., \& Verma, S. (2004). A risk reduction approach for schizophrenia: the early psychosis intervention programme. Ann Acad Med Singapore, 33, 630-635.

de, Koning, M. B., Bloemen, O. J. N., van, Amelsvoort, T. A. M. J., Becker, H. E., Nieman, D. H., Van Der Gaag, M., \& Linszen, D. H. (2009). Early intervention in patients at ultra high risk of psychosis: benefits and risks. Acta Psychiatr Scand, 119, 426-42. http://dx.doi.org/10.1111/j.1600-0447.2009.01372.x

Esterberg, M. L., Compton, M. T., McGee, R., Shim, R., \& Hochman, K. (2008). Knowledge about Schizophrenia and Social Distance toward Individuals with Schizophrenia: A Survey among Predominantly Low-Income, Urban, African American Community Members. Journal of Psychiatric Practice, 14(2), 86-93. http://dx.doi.org/10.1097/01.pra.0000314315.94791.80

Kobayashi, H., Nemoto, T., Koshikawa, H., Osono, Y., Yamazawa, R., Murakami, M., Kashima, H., \& Mizuno, M. (2008). A self-reported instrument for Prodromal symptoms of psychosis: testing the clinical validity of the PRIME Screen-Revised (PS-R) in a Japanese population. Schizophrenia Research, 106, 356-362. http://dx.doi.org/10.1016/j.schres.2008.08.018

Lincoln, C. V., \& McGorry, P. (1995). Who cares? Pathways to psychiatric care for young people experiencing a first episode of psychosis. Psychiatric Serv., 46, 1166-1171.

Torrey, E. F. (2006). Surviving Schizophrenia: A Manual for Families, Patients, and Providers (Fifth Edition). Harpercollins.

Van, O. J., \& Delespaul, P. (2005). Toward a world consensus on prevention of schizophrenia. Dialogues Clin Neurosci., 7, 53-67.

Yamazawa, R., Mizuno, M, Nemoto, T., Miura, Y., Murakami, M., \& Kashima, H. (2004). Duration of untreated psychosis and pathway to psychiatric services in first-episode schizophrenia. Psychiatry Clin Neurosci, 58, 76-81. http://dx.doi.org/10.1111/j.1440-1819.2004.01196.x

Yoshii, H., Watanabe, Y., Kitamura, H., Chen, J., \& Akazawa, K. (2011). Effect of an education program on improving knowledge of schizophrenia among parents of junior and senior high school students in Japan. BMC Public Health, 11, 323. http://dx.doi.org/10.1186\%2F1471-2458-11-323

Yoshii, H., Watanabe, Y., Kitamura, H., Nan, Z., \& Akazawa, K. (2012). Effect of an education program on improving help-seeking among parents of junior and senior high school students in Japan. Global Journal of Health Scienc, 4(1), 33-41. http://dx.doi.org/10.5539/gjhs.v4n1p33

Yung, A. R., Killackey, E., Hetrick, S. E., Parker, A. G., Schultze-Lutter, F., Klosterkoetter, J., ... Mcgorry, P. D. (2007). The prevention of schizophrenia. Int Rev Psychiatry, 19, 633-646. http://dx.doi.org/10.1080/09540260701797803 